\title{
Mutations in the Chloride Channel Gene, CLCNKB, Leading to a Mixed Bartter-Gitelman Phenotype
}

\author{
NIKOLA JECK, MARTIN KONRAD, MELANIE PETERS, STEFANIE WEBER, \\ KLAUS E. BONZEL, AND HANNSJÖRG W. SEYBERTH \\ Department of Pediatrics, Philipps University, D-35037 Marburg, Germany [N.J., M.K., M.P., S.W., \\ H.W.S.]; and University Children's Hospital, D-45122 Essen, Germany [K.E.B.]
}

\begin{abstract}
ABST
Gitelman syndrome is an inherited renal disorder character-
ized by impaired $\mathrm{NaCl}$ reabsorption in the distal convoluted
tubule and secondary hypokalemic alkalosis. In clinical practice,
it is distinguished from other hypokalemic tubulopathies by the
presence of both hypomagnesemia and normocalcemic hypocal-
ciuria. To date, only mutations in a single gene encoding the
thiazide-sensitive NaCl cotransporter have been found as the
molecular basis of GS. We describe three unrelated patients
presenting with the typical laboratory findings of GS. Mutational
analysis in these patients revealed no abnormality in the
SLC12A3 gene. Instead, all patients were found to carry previ-
ously described mutations in the $C L C N K B$ gene, which encodes
the kidney-specific chloride channel ClC-Kb, raising the possi-
bility of genetic heterogeneity. Review of the medical histories
revealed manifestation of the disease within the first year of life
in all cases. Clinical presentation included episodes of dehydra-
tion, weakness, and failure to thrive, much more suggestive of
classic Bartter syndrome than of GS. The coexistence of hypo-
\end{abstract}
GS (MIM 263800) is an inherited renal tubular disorder characterized by impaired conservation of potassium and magnesium (1). The mode of inheritance is autosomal-recessive. The first clinical presentation is usually observed during childhood or adolescence and may include transient episodes of weakness, paresthesia, and tetany. The course of disease is generally mild and some patients even remain asymptomatic $(2,3,4)$. GS patients share several biochemical findings with the more severe cBS, such as hypokalemia, metabolic alkalosis, and elevated plasma aldosterone levels (5). However, the coexistence of hypomagnesemia and hypocalciuria is considered a pathognomonic laboratory finding in GS that allows the differentiation from $\mathrm{cBS}(6)$.

Both the observation that the electrolyte disturbances in GS resemble the effect of chronic thiazide administration $(7,8)$ and

Received January 14, 2000; accepted July 1, 2000.

Correspondence and reprint requests: Hannsjörg W Seyberth, M.D., Department of Pediatrics, Philipps University, Deutschhausstrasse 12, D-35037 Marburg, Germany.

Supported by the German Research Society (DFG-Se 263/15-1, DFG-Ko 1480/3-2). magnesemia and hypocalciuria was not present from the beginning. In the follow-up, however, a drop of both parameters below normal range was a consistent finding reflecting a transition from cBS to GS phenotype. The phenotypic overlap may indicate a physiologic cooperation of the apical thiazide-sensitive $\mathrm{NaCl}$ cotransporter and the basolateral chloride channel for salt reabsorption in the distal convoluted tubule. (Pediatr Res 48: 754758, 2000)

Abbreviations
GS, Gitelman syndrome
cBS, classic Bartter syndrome
DCT, distal convoluted tubule
NCCT, thiazide-sensitive NaCl cotransporter
ClC-Kb, kidney-specific basolateral chloride channel
TAL, thick ascending limb of Henle's loop
HPS/aBS, hyperprostaglandin E/antenatal Bartter syndrome

the results of clearance studies have pointed to a defect in the distal thiazide-sensitive sodium chloride transport (9). This hypothesis has been substantiated by the demonstration that GS is caused by mutations in the SLC12A3 gene, which encodes the NCCT of the DCT (10). Meanwhile, more than 100 mutations throughout the NCCT have been described in GS patients, suggesting genetic homogeneity (4, 11, 12). Several mutations that cause GS have recently been found to be nonfunctional because the mutant NCCT is not processed normally, probably activating the "quality control" mechanisms of the endoplasmic reticulum (13).

The NCCT defect directly leads to $\mathrm{NaCl}$ wasting, activation of the renin-angiotensin system, increased aldosterone levels, and increased electrogenic sodium reabsorption via the epithelial sodium channel of the distal nephron in exchange for $\mathrm{K}^{+}$ and $\mathrm{H}^{+}$, accounting for hypokalemic alkalosis. The exact mechanisms underlying hypocalciuria and hypermagnesiuria are not fully elucidated yet, but there is enough evidence that both abnormalities are direct consequences of the primary 
defect. Both hypocalciuria and hypermagnesiuria are observed after administration of thiazide diuretics that inhibit the NCCT $(7,14)$. Moreover, an analogous dissociation of renal handling of $\mathrm{Ca}^{2+}$ and $\mathrm{Mg}^{2+}$ is observed in NCCT-deficient mice (15).

We report on three unrelated patients in whom renal salt wasting coincides with hypomagnesemia and hypocalciuria. Surprisingly, all three children were found to carry mutations in the $C L C N K B$ gene encoding the kidney-specific chloride channel $\mathrm{ClC}-\mathrm{Kb}$, raising the question of genetic heterogeneity in GS.

\section{SUBJECTS AND METHODS}

GS patients. The three patients were referred to our hospital for molecular analyses at the age of 3,5, and 7 years. All of them were offspring of consanguineous parents. Diagnosis of GS was based on the following criteria described by Bettinelli et al. (3): (1) hypokalemia of renal origin, defined as plasma potassium $<3.6 \mathrm{mM}$ in the presence of inappropriately high potassium excretion (fractional excretion of potassium $>16 \%$ ); (2) hypomagnesemia of renal origin, defined as plasma magnesium $<0.65 \mathrm{mM}$ in the presence of inappropriately high magnesium excretion (fractional excretion of magnesium $>4 \%$ ); (3) hypocalciuria, defined as daily urinary calcium excretion $<2 \mathrm{mg} / \mathrm{kg}$, or urinary calcium/creatinine molar ratio $\leq 0.10$. The laboratory data and medication at the time of referral to our hospital are indicated in Table 1. Patient $\mathrm{C}$ was reported previously (16).

Genetic analyses. Genomic DNA was extracted from peripheral blood lymphocytes by standard procedures. Haplotype construction was performed with six dinucleotide repeat markers for each loci 16q13 (SLC12A3) and 1p36 (CLCNKB) (Fig. 1) following protocols previously described (17). The resulting PCR fragments were sized on a $6 \%$ nondenaturating polyacrylamide gel in an ALF Express DNA SequencerTM using the ALF Fragment Manager ${ }^{\mathrm{TM}} 1.0$ software (Pharmacia Biotech, Uppsala, Sweden).

Both the SLC12A3 gene and the CLCNKB gene were screened for mobility shifts by SSCA (18) using intronic primers previously published $(10,19)$. DNA segments yielding aberrant banding patterns were reamplified and subjected to direct sequencing on an ALF Express DNA Sequencer ${ }^{\mathrm{TM}}$ following the protocols provided by the manufacturer.

These studies were approved by the local ethics committee and informed consent was obtained from the parents.

\section{RESULTS}

Genotypes. Mutational screening of the whole coding region of the SLC12A3 gene by SSCA did not reveal any abnormality in the three patients. To clarify whether the $S L C 12 A 3$ gene was involved in the disease at all, we subsequently performed haplotype analysis with microsatellites closely flanking the gene locus on chromosome 16q13 (Fig. 1). None of the patients revealed a region of homozygosity at this locus, confirming that the phenotype was not related to mutations in the $S L C 12 \mathrm{A3}$ gene. Instead, further analyses revealed haplotypes that were highly suggestive for cosegregation of the phenotype with chromosome 1p36 (Fig. 1). Because the CLCNKB gene encoding the kidney-specific chloride channel $\mathrm{ClC}-\mathrm{Kb}$ localizes to this cytogenetic region, we subsequently screened our patients for $C L C N K B$ mutations and, indeed, all three patients were found to carry pathogenic mutations in this gene. Patients A and $\mathrm{B}$ were shown to carry a homozygous deletion of the complete $C L C N K B$ gene (Fig. 2A). Deletions of the entire gene were described previously $(16,19)$, and thought to be due to the close vicinity to the highly homologous CLCNKA gene, which might predispose to nonhomologous crossing over. In patient $\mathrm{C}$, we identified a homozygous exchange of guanine for adenine at the consensus acceptor splice site of intron 7 (IVS7-2) (Fig. 2B). This mutation had already been found in an unrelated cBS patient (16), whereas it was not found in 100 control alleles.

Phenotypes. At the time of genetic counseling, all three children presented with the biochemical findings consistent with the diagnosis of GS (Table 1). Review of the medical histories, however, revealed an early onset of the disease within the first year of life in all three cases. After normal pregnancy and birth at term all three infants suffered from weakness and failure to thrive beginning at the ages of 1 (A), 2 (B), and 11 (C) months. In addition, patients A and B experienced one episode of dehydration in the context of a

Table 1. Important laboratory findings and medication in the three GS patients

\begin{tabular}{|c|c|c|c|c|}
\hline & Patient A & Patient B & Patient C & Normal range \\
\hline $\mathrm{K}^{+}$ & 3.5 & 3.4 & 3.3 & $3.6-4.5(\mathrm{mmol} / \mathrm{L})$ \\
\hline $\mathrm{HCO}_{3}{ }^{-}$ & 30.1 & 31 & 31.5 & $23-27(\mathrm{mmol} / \mathrm{L})$ \\
\hline Aldosterone & 68.8 & nd & 34.2 & $5-13.4(\mathrm{ng} / \mathrm{dL})$ \\
\hline $\mathrm{FeK}$ & 42 & 67 & 30 & $<16(\%)$ \\
\hline $\mathrm{FeMg}$ & 7.9 & nd & 6 & $<4(\%)$ \\
\hline Urinary calcium excretion & 0.57 & 0.9 & 0.62 & $2-4(\mathrm{mg} / \mathrm{kg} / \mathrm{d})$ \\
\hline Creatinine clearance & 86 & 124 & 126 & $80-120\left(\mathrm{~mL} / \mathrm{min} / 1.7 \mathrm{~m}^{2}\right)$ \\
\hline \multicolumn{5}{|l|}{ Medication } \\
\hline Potassium chloride & 3.4 & 10 & 3 & $(\mathrm{mmol} / \mathrm{kg} / \mathrm{d})$ \\
\hline Sodium chloride & - & 4 & - & $(\mathrm{mmol} / \mathrm{kg} / \mathrm{d})$ \\
\hline Magnesium glutamate & - & 600 & - & $(\mu \mathrm{mol} / \mathrm{kg} / \mathrm{d})$ \\
\hline Indomethacin & 3 & 4 & 3 & $(\mathrm{mg} / \mathrm{kg} / \mathrm{d})$ \\
\hline
\end{tabular}

* Value for $24 \mathrm{~h}$ urine. 

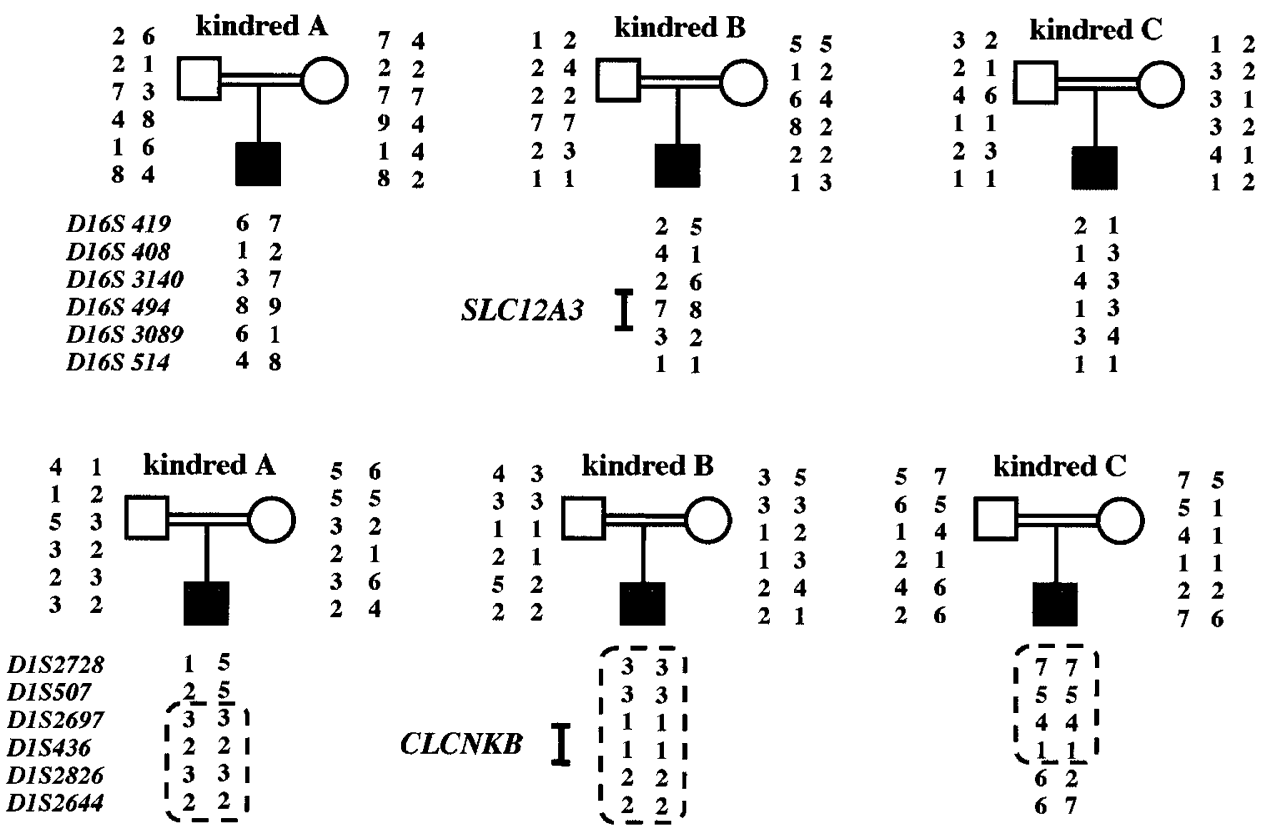

Figure 1. Pedigrees and haplotypes in three consanguineous GS/cBS kindreds. Upper panel: Lack of homozygosity for microsatellites linked to the $S L C 12 A 3$ locus on chromosome 16q13. Lower panel: Cosegregation of the phenotype with the CLCNKB locus on chromosome $1 \mathrm{p} 36$ indicated by homozygosity by descent.

gastrointestinal infection. The first laboratory examination consistently revealed plasma potassium levels below $3.0 \mathrm{mM}$, metabolic alkalosis, and hyperreninemic hyperaldosteronism. Plasma levels of magnesium were initially normal with the exception of patient C. Moreover, renal and systemic prostaglandin $\mathrm{E}$ formation was elevated in all three patients, which led to the introduction of indomethacin treatment in addition to potassium supplementation. Under this treatment, the patients were doing well. Urine osmolality, determined in 24-hour urine, ranged from 433 to $682 \mathrm{mmol} / \mathrm{kg}$ (median 588, $n=12$ ) and from 289 to $727 \mathrm{mmol} / \mathrm{kg}$ (median 600,n=9) in patients $\mathrm{A}$ and C, respectively. No further episodes of major electrolyte disturbances have occurred and physical development has been within normal range.

During follow-up, all three patients developed hypomagnesemia and urinary calcium excretion below $1 \mathrm{mg} / \mathrm{kg} / \mathrm{d}$ (Fig. 3). Patient $B$ received permanent magnesium supplements from $2 \mathrm{y}$ of age onward, whereas patient $\mathrm{C}$ required magnesium supplementation only in the initial phase. Persistence of both hypomagnesemia and hypocalciuria after withdrawal of indomethacin could be demonstrated in patients $\mathrm{A}$ and $\mathrm{C}$. When indomethacin was discontinued in patient $\mathrm{B}$, plasma magnesium concentration was $0.5 \mathrm{mM}$ only. Concurrent urinary calcium was not available.

\section{DISCUSSION}

The syndrome of familial hypokalemia-hypomagnesemia or GS is thought to represent a genetically homogeneous renal disorder. Mutations in a single gene, SLC12A3, have been consistently found in nearly all GS families studied $(4,10-12)$. Only a few investigators had conceded the fact that in certain GS patients no mutant $S L C 12 A 3$ allele had been identified (12, 20). It was likely that these rare unsolved cases might reflect the limited sensitivity of the screening methods. Secondly, the pathogenic mutations might have been located in the noncoding region of $S L C 12 A 3$, such as the promotor region, which were generally not included in the mutation analyses.

However, the three kindreds with $C L C N K B$ mutations described in this report raise the question of genetic heterogeneity in GS. Although our patients did not present with the typical GS phenotype, they reproducibly shared both hypomagnesemia and hypocalciuria, which is thought to be a pathognomonic pattern of GS (6). The additional findings, such as manifestation during the first year of life, volume depletion, failure to thrive, and hyperprostaglandinuria are certainly much more compatible with cBS than the GS phenotype $(21,22)$. Indeed, mutations in the $C L C N K B$ gene, which were originally found to be related to a very variable phenotype (19), have subsequently been described as the major molecular defect of cBS (16). In this regard, the clinical presentation of our three patients may be best described as a mixed Bartter-Gitelman phenotype. So far, the present data do not contradict the concept of genetic homogeneity of GS, but may stimulate the search of mutation in more typical GS patients with no SLC12A3 mutation.

The phenotypic overlap between GS and cBS is not a novel observation. Recently, the concomitant occurrence of GS and cBS in the same family has been reported (23). One child presented a phenotype of renal salt wasting with isolated hypokalemic alkalosis, and a sibling additionally exhibited hypomagnesemia and hypocalciuria. Moreover, a controversial discussion lasted over nearly three decades about how to distinguish these tubular disorders $(24,25)$. Hypomagnesemia is by definition a feature of GS (1), but it is also present in approximately one-third of the patients with Bartter syndrome (6), although very low levels are unusual in the latter. Even the two patients described in Bartter's original report (5) presented with tetany, which is typically observed in GS, most likely due 

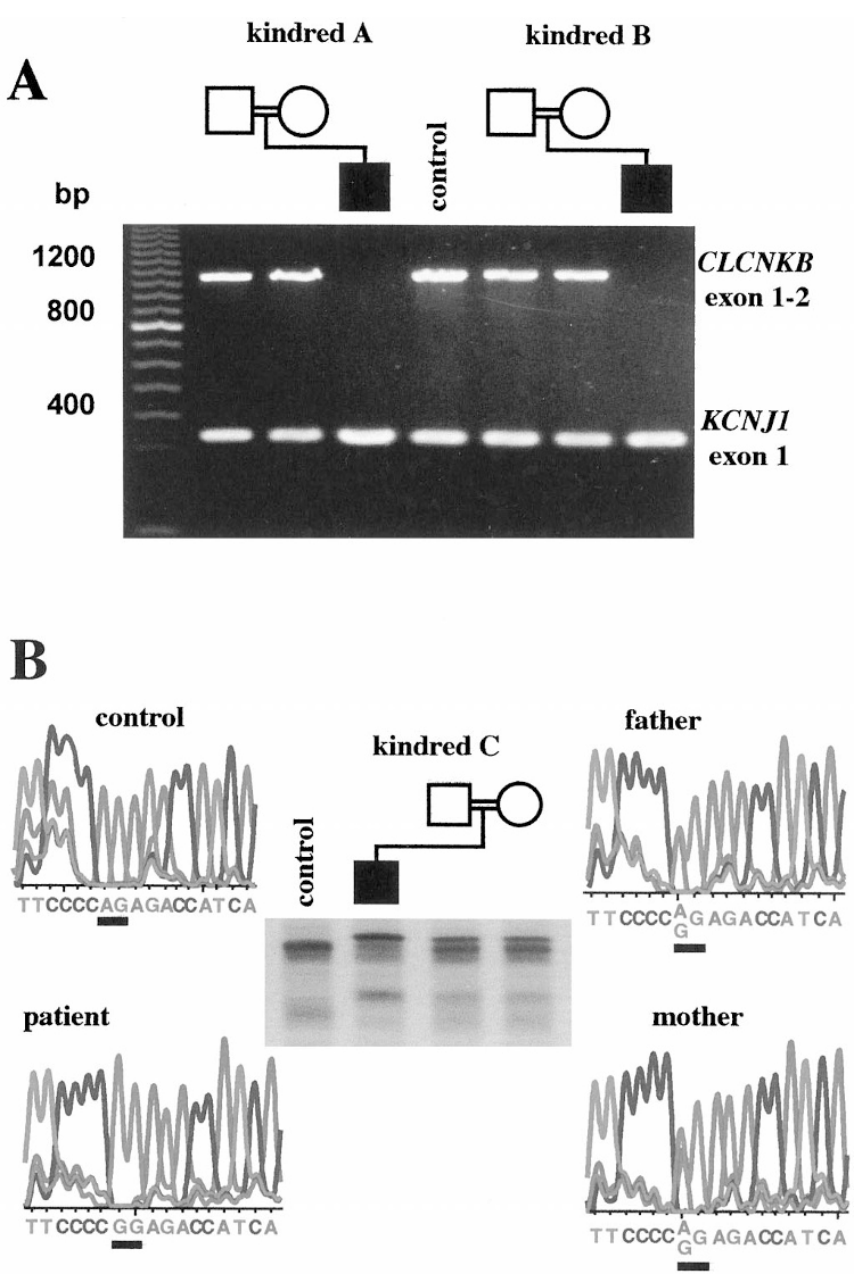

Figure 2. Molecular basis in the three patients with GS/cBS phenotype.(A) Patients A and B bear a deletion of the whole coding region of the CLCNKB gene. All 19 exons were amplified from genomic DNA and separated on agarose gels. The picture shows the deletion of a CLCNKB segment spanning exon 1 and 2. Coamplification of an unrelated gene segment (KCNJ1) was used for internal control. $(B)$ Single strand conformation polymorphism analysis (SSCA) of exon 8 of the $C L C N K B$ gene revealed an abnormal conformer in kindred C. Direct sequencing revealed a homozygous exchange from adenine to guanine affecting the 3 'consensus splice site of intron 7 .

to low plasma magnesium levels. Instead, renal handling of calcium was found to be a more specific parameter to distinguish between GS and cBS (6).

After a large number of individuals affected by $S L C 12 A 3$ mutations had been described, it became apparent that the phenotypic consequences are rather heterogeneous. The age at clinical presentation was highly variable, ranging from 6 mo to $60 \mathrm{y}$ of age (12). Bettinelli et al. reported failure to thrive (6) and growth retardation (26) in a subset of GS patients. In our hospital, we are following several GS patients carrying SLC12A3 mutations, who consistently showed moderate hyperprostaglandinuria and who significantly benefited from indomethacin therapy (27).

Taken together, there exists some variability of the phenotypes induced by mutations in either SLC12A3 or CLCNKB $(19,16)$ leading in part to overlapping clinical features. This overlap makes it more difficult to clearly separate GS from cBS.
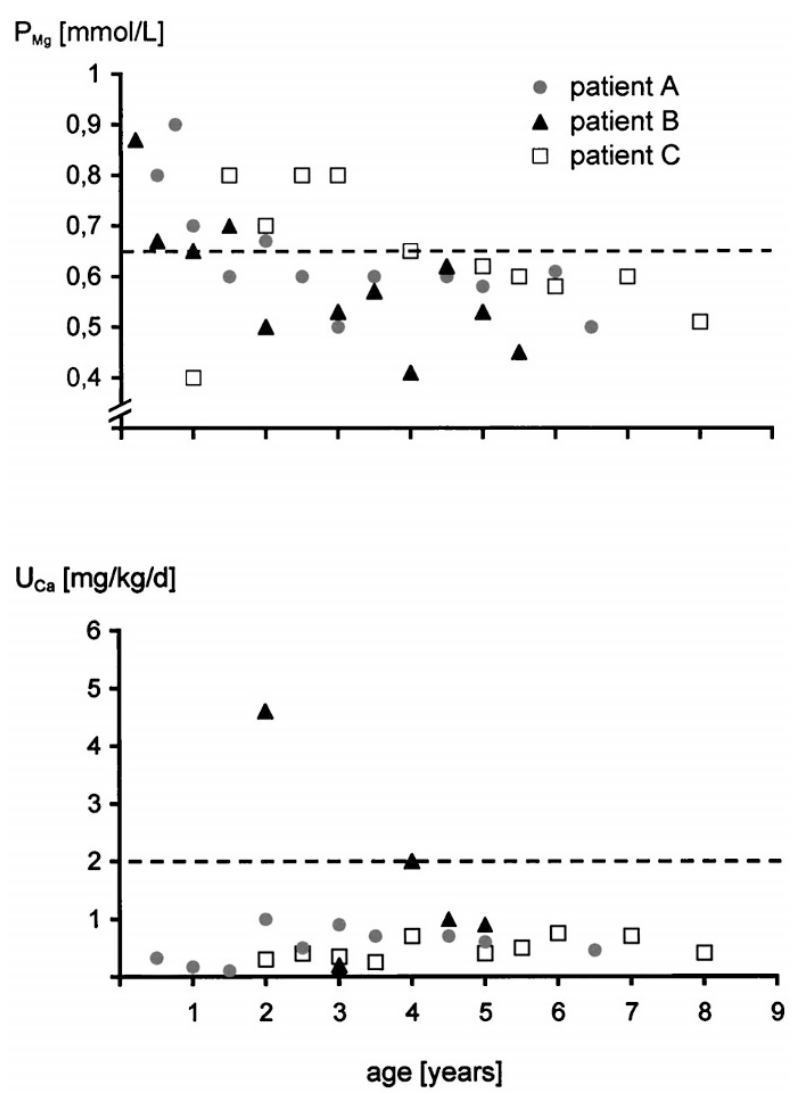

Figure 3. Follow-up of plasma magnesium levels $\left(\mathrm{P}_{\mathrm{Mg}}\right)$ and urinary calcium excretion $\left(\mathrm{U}_{\mathrm{Ca}}\right)$ in three patients with $C L C N K B$ mutations. The dotted line indicates the lower normal level.

Moreover, the phenotypic similarities lead to the hypothesis that there might be a close functional relationship between the two disease-related proteins, NCCT and $\mathrm{ClC}-\mathrm{Kb}$, in transepithelial electrolyte transport. This hypothesis could provide us with the answer to the question of how defective $\mathrm{ClC}-\mathrm{Kb}$ could lead to concomitant occurrence of hypomagnesemia and hypocalciuria.

The physiologic role of $\mathrm{ClC}-\mathrm{Kb}$ and its functional cooperation with the various transport systems of the renal tubule has not yet been fully established. In the rat, the $\mathrm{ClC}-\mathrm{Kb}$ homologue seems to be broadly expressed in the distal parts of the renal tubule (28). Transcripts of the chloride channel gene were found in tubular epithelial cells from medullary and cortical $\mathrm{TAL}$, distal tubule, and collecting duct. $\mathrm{ClC}-\mathrm{Kb}$ is polarized to the basolateral membrane and is most likely responsible for the chloride efflux from the cell into the blood stream.

A defect of the basolateral chloride channel is expected to result in an impaired chloride reabsorption in the distal nephron. The phenotypic consequences of impaired salt reabsorption exclusively in the TAL are demonstrable in HPS/aBS (27). Characteristics of this tubular disorder are saliuretic polyuria, isosthenuria, and hypercalciuria (29). Plasma magnesium levels are generally normal. The phenotype in our patients as well as in the majority of individuals affected by CLCNKB mutations clearly did not correspond to a TAL disorder (16). Affected individuals maintain their urinary concentrating capacity at least to a certain extent and display 
normal or, as in our cases, even low urinary calcium excretion. Therefore, $\mathrm{ClC}-\mathrm{Kb}$ apparently does not play an irreplaceable role in transcellular chloride reabsorption in the TAL. Indeed, Greger et al. (30) proposed the coexistence of chloride conductance and electroneutral K-Cl symport through the basolateral membrane of TAL epithelial cells. This suggestion has been substantiated by demonstration that the $\mathrm{K}-\mathrm{Cl}$ cotransporter $\mathrm{hKCC} 1$ is expressed in this part of the nephron and may target to the basolateral membrane (31).

The dissociation of renal calcium and magnesium handling with hypocalciuria and hypermagnesiuria in our three patients points to an impaired salt reabsorption more distal from the TAL. Luminal $\mathrm{NaCl}$ reabsorption into the distal convoluted tubular epithelial cells is mediated by the NCCT.

Defective function of the NCCT results in a reduction of the intracellular sodium concentration probably followed by an activation of the basolateral $\mathrm{Na}-\mathrm{Ca}$ exchanger. The $\mathrm{Na}-\mathrm{Ca}$ exchanger might establish a gradient (low intracellular $\mathrm{Ca}^{2+}$ ) that is responsible for increased calcium uptake from the tubular lumen to the cell causing hypocalciuria (32). The coincident hypermagnesiuria remains to be explained. It has been hypothesized that the basis of diminished magnesium absorption in the DCT is due to aldosterone-induced hypokalemia secondary to salt and volume depletion (33). Alternatively, the inhibition of an apical $\mathrm{Na}-\mathrm{Mg}$ exchanger through low intracellular sodium concentration has been proposed (34). Therefore, the mechanisms underlying hypocalciuria and hypermagnesiuria appear to be directly related to impaired sodium uptake in the DCT. The hypomagnesemic-hypocalciuric phenotype of our patients further suggests that not only mutations in NCCT but also secondary inhibition of NCCT by intracellular chloride ion accumulation as a consequence of defective $\mathrm{ClC}-\mathrm{Kb}$ could abolish transepithelial salt reabsorption in DCT. This observation provides further evidence that $\mathrm{ClC}-\mathrm{Kb}$ channels play an important physiologic role in this part of the nephron.

In summary, there is no simple genotype-phenotype correlation in patients with $C L C N K B$ mutations. The phenotypic heterogeneity probably reflects the wide distribution of $\mathrm{ClC}-\mathrm{Kb}$ in the distal nephron. The potential for activating alternative routes for basolateral chloride secretion in the particular nephron segment might be crucial for the individual clinical presentation: the classic Bartter phenotype or the disorder of the DCT.

\section{REFERENCES}

1. Gitelman HJ, Graham JB, Welt LG 1966 A new familial disorder characterized by hypokalemia and hypomagnesemia. Trans Assoc Am Phys 79:221-235

2. Gladziwa U, Schwarz R, Gitter AH, Bijmann J, Seyberth HW, Beck F, Ritz E, Gross P 1995 Chronic hypokalaemia of adults: Gitelman's syndrome is frequent but classical Bartter's syndrome is rare. Nephrol Dial Transplant 10:1607-1613

3. Bettinelli A, Bianchetti MG, Borella A, Volpini E, Metta MG, Basilico E, Selicorni A, Bargellini A, Grassi MR 1995 Genetic heterogeneity in tubular hypomagnesemiahypokalemia (Gitelman's syndrome). Kidney Int 47:547-551

4. Lemmink HH, Knoers NVAM, Karolyi L, van Dijk H, Niaudet P, Antignac C, Guay-Woodford LM, Goodyer PR, Carel J-C, Hermes A, Seyberth HW, Monnens LAH, van den Heuvel LPWJ 1998 Novel mutations in the thiazide-sensitive $\mathrm{NaC}$ cotransporter gene in patients with Gitelman's syndrome with predominant localization to the C-terminal domain. Kidney Int 54:720-730

5. Bartter FC, Pronove P, Gill JR, MacCardle RC 1962 Hyperplasia of the juxtaglomerular complex with hyperaldosteronism and hypokalemic alkalosis. A new syndrome. Am J Med 33:811-828
6. Bettinelli A, Bianchetti MG, Girardin E, Caringella A, Cecconi M, Appiani AC, Pavanello L, Gastaldi R, Isimbaldi C, Lama G, Marchesoni C, Matteucci C, Patriarca P, DiNatale B, Setzu C, Vitucci P 1992 Use of calcium excretion values to distinguish two forms of primary renal tubular hypokalemic alkalosis: Bartter and Gitelman's syndromes. J Pediatr 120:38-43

7. Hollifield JW 1989 Thiazide treatment of systemic hypertension: effect on serum magnesium and ventricular ectopic activity. Am J Cardiol 63:G22-G25

8. Velazquez H, Ellison DH, Wright FS 1992 Luminal influences on potassium secretion: chloride, sodium and thiazide diuretics. Am J Physiol 262:F1076-F1082

9. Sutton RA, Marichak V, Halebe A, Wilkins GE 1992 Bartter's syndrome: evidence suggesting a distal tubular defect in a hypocalciuric variant of the syndrome. Miner Electrol Metab 18:43-51

10. Simon DB, Nelson-Williams C, Bia MJ, Ellison D, Karet FE, Molina AM, Vaara I, Iwata F, Cushner HM, Koolen M, Gainza FJ, Gitelman HJ, Lifton RP 1996 Gitelman's variant of Bartter syndrome, inherited hypokalemic alkalosis, is caused by mutations in the thiazide-sensitive $\mathrm{Na}-\mathrm{Cl}$ cotransporter. Nat Genet 12:24-30

11. Mastroianni N, Bettinelli A, Bianchetti M, Colussi G, de Fusco M, Sereni F, Ballabio A, Casari G 1996 Novel molecular variants of the $\mathrm{Na}-\mathrm{Cl}$ cotransporter gene are responsible for Gitelman's syndrome. Am J Hum Genet 59:1019-1026

12. Simon DB, Crut DN, Lu Y, Lifton RP 1998 Genotype-phenotype correlation of the NCCT and Gitelman's syndrome. J Am Soc Nephrol 9:111A (abstr)

13. Kunchaparty S, Palsco M, Berkman J, Velazquez H, Desir GV, Bernstein P, Reilly RF, Ellison DH 1999 Defective processing and expression of thiazide-sensitive $\mathrm{Na}-\mathrm{Cl}$ cotransporter as a cause of Gitelman's syndrome. Am J Physiol 277:F643-F649

14. Stanton BA 1990 Cellular actions of thiazide diuretics in the distal tubule. J Am Soc Nephrol 1:832-836

15. Schultheis PJ, Lorenz JN, Meneton P, Nieman ML, Riddle TM, Flagella M, Duffy JJ, Doetschman T, Miller ML, Shull GE 1998 Phenotype resembling Gitelman's syndrome in mice lacking the apical $\mathrm{Na}+\mathrm{Cl}-$ cotransporter of the distal convoluted tubule. J Biol Chem 273:29150-29155

16. Konrad M, Vollmer M, Lemmink HH, van der Heuvel B, Jeck N, Vargas-Poussou R, Smith A, Ruf R, Deschenes G, Antignac C, Guay-Woodford LM, Koers NVAM, Seyberth HW, Feldman D, Hildebrandt F 2000 Mutations in the chloride channel gene CLCNKB as a cause of classic Bartter syndrome. J Am Soc Nephrol 11:1449-1459

17. Karolyi L, Ziegler A, Pollak M, Fischbach M, Grzeschik KH, Koch MC, Seyberth HW 1996 Gitelman's syndrome is genetically distinct from other forms of Bartter's syndrome. Pediatr Nephrol 10:551-554

18. Orita M, Suzuki YH, Sakiya T, Hayaski K 1989 Rapid and sensitive detection of point mutations and DNA polymorphisms using the polymerase chain reaction. Genomics 5:874-879

19. Simon DB, Bindra RS, Mansfield TA, Nelso-Williams C, Mendonca E, Stone R, Schurmann S, Nayir A, Alpay H, Bakkaloglu A, Rodriguez-Soriano J, Morales JM, Saniad SA, Taylor CM, Pilz D, Brem A, Trachtman H, Griswold W, Richard GA, John E, Lifton RP 1997 Mutations in the chloride channel gene, CLCNKB, cause Bartter's syndrome type III. Nat Genet 17:171-178

20. Bettinelli A, Ciarmatori S, Colussi G, Vezzoli G, Gastaldi R, Cecconi M, Donati MA, Sacco M, Caringella A, Appiani AC, Sereni F, Casari G 1998 Phenotype-genotype correlations in patients with primary renal tubular metabolic alkalosis. J Am Soc Nephrol 9:386A (abstr)

21. Seyberth HW, Soergel M, Köckerling A 1998 Hypokalemic tubular disorders: the hyperprostaglandin E syndrome and Gitelman-Bartter syndrome. In: Davidson AM, Cameron JS, Grünfeld JP, Kerr DN, Ritz E (eds) Oxford Textbook of Clinical Nephrology, 2nd Ed. Oxford University Press, Oxford, pp 1085-1094

22. Rodriguez-Soriano J 1999 Tubular disorders of electrolyte regulation. In: Barratt TM, Avner ED, Harmon WE (eds) Pediatric Nephrology, 4th Ed. Lippincott Williams \& Wilkins, Baltimore, pp 545-563

23. Turman MA 1998 Concomitant occurrence of Gitelman and Bartter syndromes in the same family? Pediatr Nephrol 12:23-25

24. Clive DM 1995 Bartter's syndrome: the unsolved puzzle. Am J Kidney Dis 25:813-823

25. McCredie DA 1996 Variants of Bartter's syndrome. Pediatr Nephrol 10:419-421

26. Bettinelli A, Rusconi R, Ciarmatori S, Righini V, Zammarchi E, Donati MA, Isimbaldi C, Bevilacqua M, Cesareo L, Tedeschi S, Garavaglia R, Casari G 1999 Gitelman disease associated with growth hormone deficiency, disturbances in vasopressin secretion and empty sella: a new hereditary renal tubular-pituitary syndrome? Pediatr Res 46:232-238

27. Köckerling A, Reinalter SC, Seyberth HW 1996 Impaired response to furosemide in hyperprostaglandin E syndrome: evidence for a tubular defect in the loop of Henle. J Pediatr 129:519-528

28. Vandewalle A, Cluzeaud F, Bens M, Kieferle S, Steinmeyer K, Jentsch TJ 1997 Localization and induction by dehydration of ClC-K chloride channels in the rat kidney. Am J Physiol 272:F678-F688

29. Seyberth HW, Rascher W, Schweer H, Kühl PG, Mehls O, Schärer K 1985 Congenital hypokalemia with hypercalciuria in preterm infants: a hyperprostaglandinuric tubular syndrome different from Bartter syndrome. J Pediatr 107:694-701

30. Greger R, Schlatter E 1983 Properties of the basolateral membrane of the cortical thick ascending limb of Henle's loop of rabbit kidney. A model for secondary active chloride transport. Pfluegers Arch 396:325-334

31. Liapis H, Nag M, Kaji DM $1998 \mathrm{~K}-\mathrm{Cl}$ cotransporter expression in the human kidney. Am J Physiol 275:C1432-C1437

32. Gesek FA, Friedman PA 1992 Mechanism of calcium transport stimulated by chlorothiazide in mouse distal convoluted tubule cells. J Clin Invest 90:429-438

33. Dai L-J, Friedman PA, Quamme GA 1997 Cellular mechanisms of chlorothiazide and potassium depletion on $\mathrm{Mg}^{2+}$ uptake in mouse distal convoluted tubule cells. Kidney Int 51:1008-1017

34. Simon DB, Lifton RP 1996 the molecular basis of inherited hypokalemic alkalosis: Bartter's and Gitelman's syndromes. Am J Physiol 271:F961-F966 